\title{
Endoscopic ultrasound-guided transjejunal rendezvous access to the common bile duct
}

The patient was an 83-year-old man with a history of gastric cancer for which he underwent total gastrectomy with Rouxen-Y esophagojejunostomy. He presented with cholestasis, and imaging revealed evidence of choledocholithiasis.

The patient's surgically altered anatomy presented a challenge for endoscopic retrograde cholangiopancreatography (ERCP). Despite multiple attempts, enteroscopy-assisted ERCP was not successful, as the papilla could not be visualized. Endoscopic ultrasound (EUS)-guided biliary ductal access was then performed. A transhepatic route was not possible as the intrahepatic ducts were not dilated. The conventional transduodenal access to the bile duct was also not possible because of the surgically altered anatomy. The EUS scope was advanced to the jejunum until fluoroscopically it was contiguous to the common bile duct (CBD). An EUS-guided transjejunal access of the common bile duct was then attempted ( $\triangleright$ Video 1 ).

With EUS guidance, a 19 gauge flexible needle was used to puncture the CBD ( Fig.1). Contrast was injected, and re- vealed dilation of the $C B D$ and a filling defect in the mid-CBD ( $\triangleright$ Fig. 2). A 0.025 inch guidewire was advanced through the CBD and coiled within the duodenum ( Fig.3). The scope was withdrawn, and an enteroscope was advanced into the biliary limb to retrieve the guidewire using a snare. The scope and guidewire were then fully withdrawn from the patient, and an adult colonoscope was advanced over the wire ( $>$ Fig.4) to the papilla. Sphincterotomy followed by sphincteroplasty to $12 \mathrm{~mm}$ were then performed. A few large stones were removed using an extraction balloon ( Fig.5), until clear bile was obtained. The largest stone measured $15 \mathrm{~mm}$ in diameter (> Fig.6)

After the procedure, the patient developed mild cholangitis and was managed conservatively with antibiotics. His temperature and liver function tests returned to normal. He was discharged home 6 days after the procedure.

Endoscopy_UCTN_Code_TTT_1AS_2AD

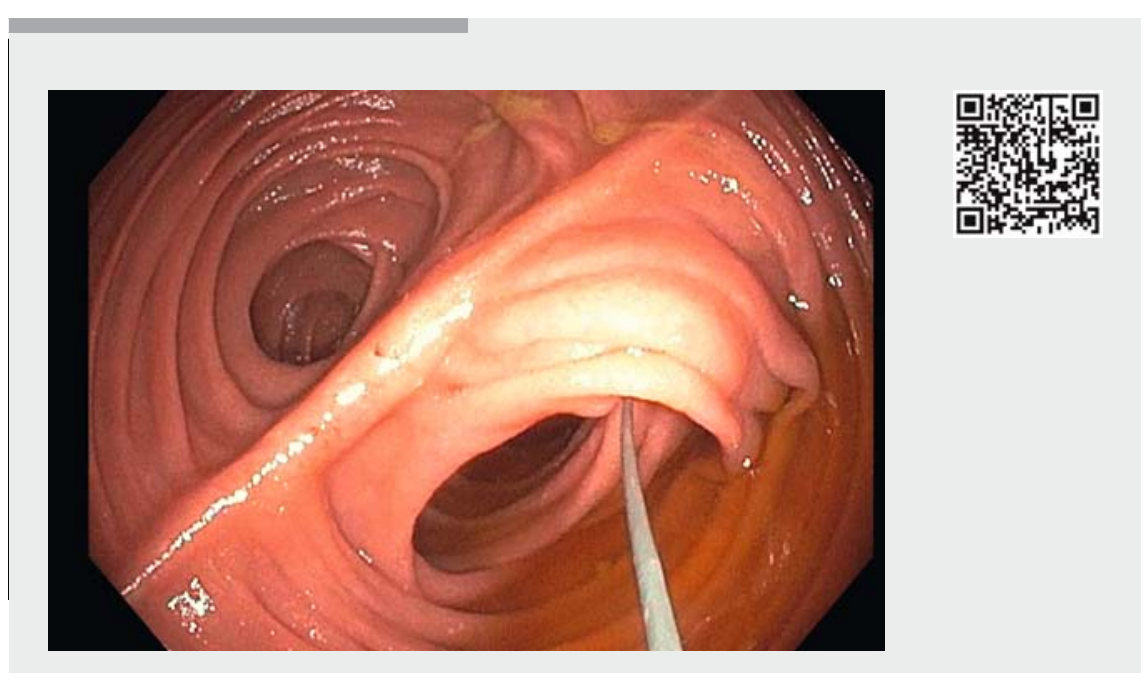

Video 1 Endoscopic ultrasound-guided transjejunal rendezvous access of the common bile duct in a patient with Roux-en-Y esophagojejunostomy.

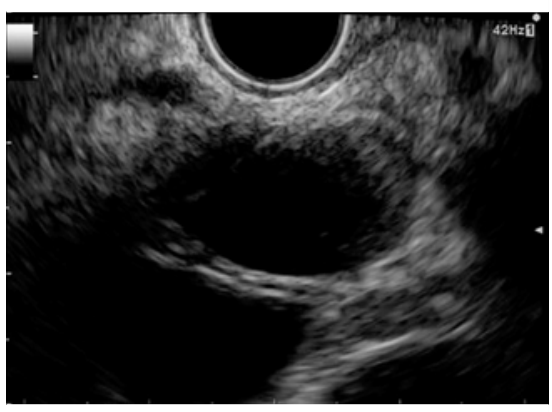

- Fig. 1 Endoscopic ultrasound-guided transjejunal access to the bile duct using a 19 gauge needle.

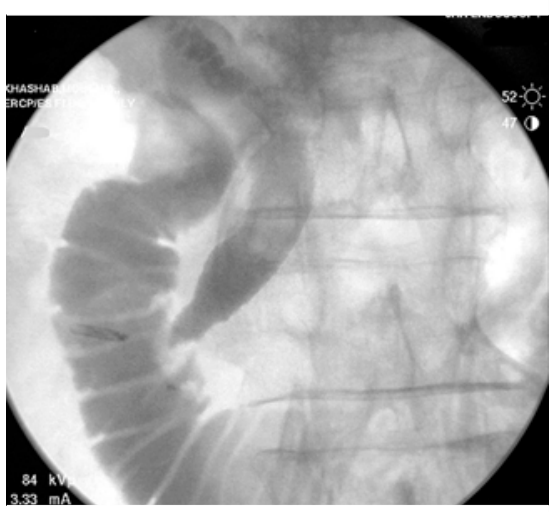

- Fig. 2 Antegrade cholangiography showing dilation of the common bile duct and a filling defect in the mid common bile duct.

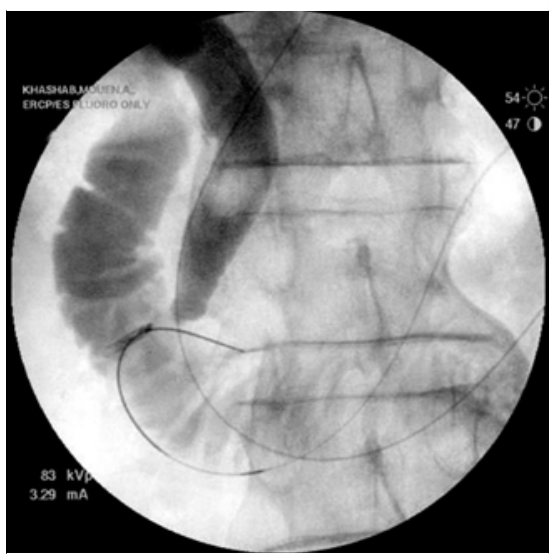

Dig. 3 Fluoroscopic image showing the wire advanced through the common bile duct and coiled in the duodenum. 


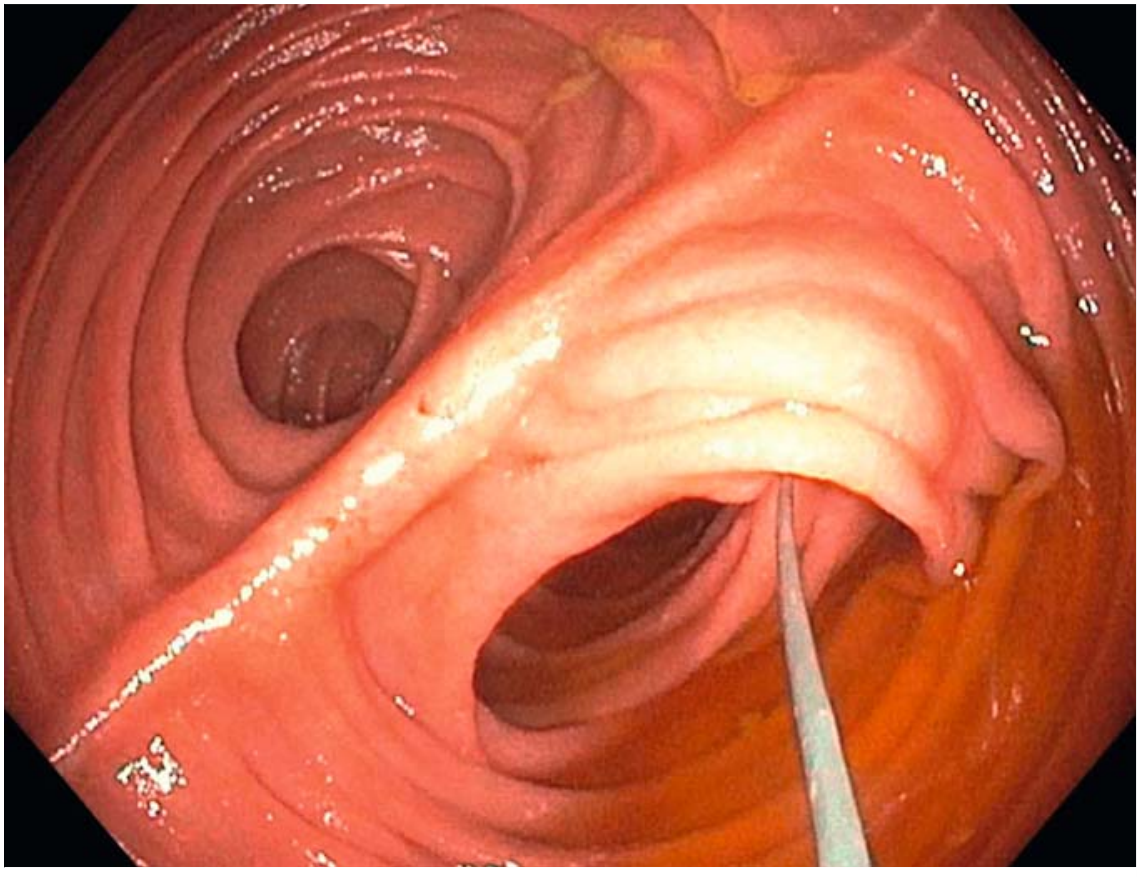

- Fig. 4 Endoscopic view showing the afferent (right) and efferent (left) limbs as the colonoscope was advanced over the wire to the papilla.

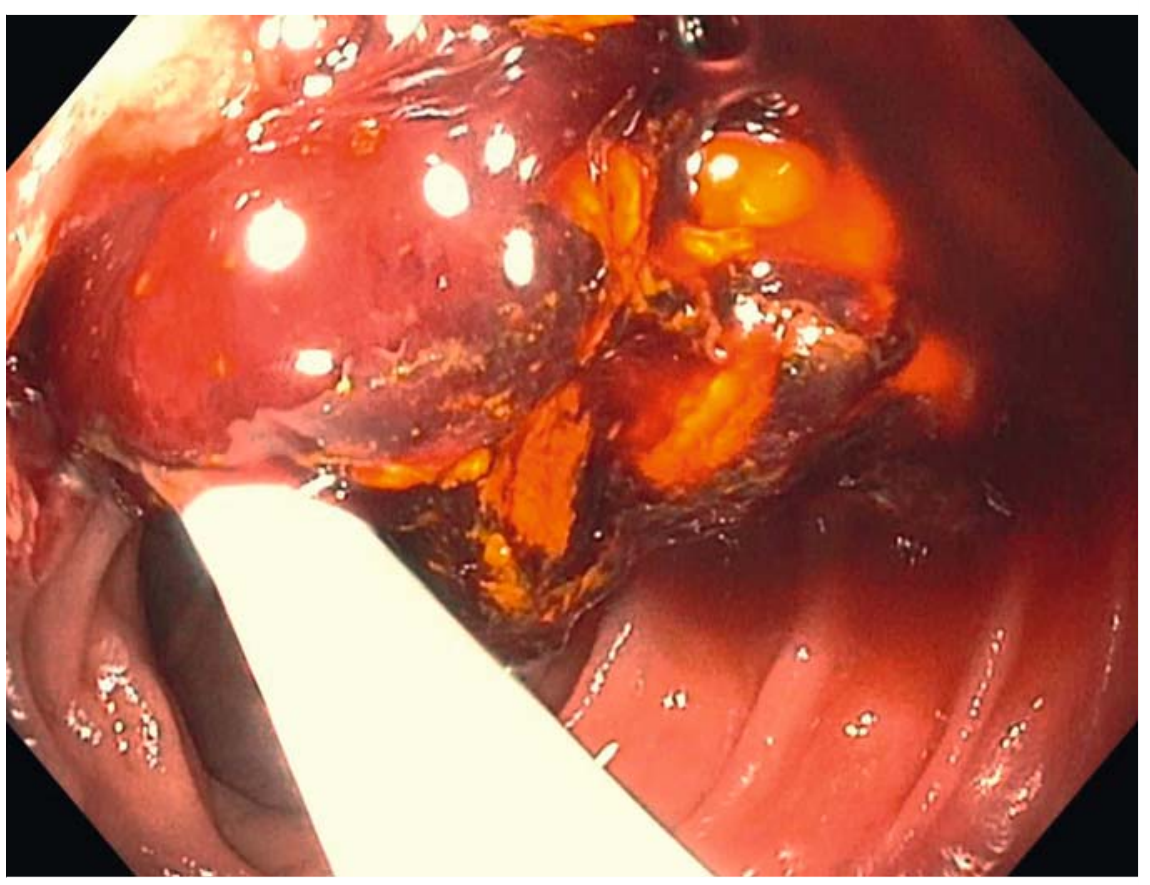

Fig. 6 Endoscopic view showing one of the larger stones removed by the extraction balloon.

\section{Competing interests}

Dr. Khashab is a consultant for Boston Scientific. Dr. Kumbhari is a consultant for Boston Scientific and Apollo Endosurgery.
The Authors

Lea E. Fayad, Yen-I Chen, Yamile H. Chavez, Vivek Kumbhari, Mouen A. Khashab Department of Medicine and Division of Gastroenterology and Hepatology, The Johns

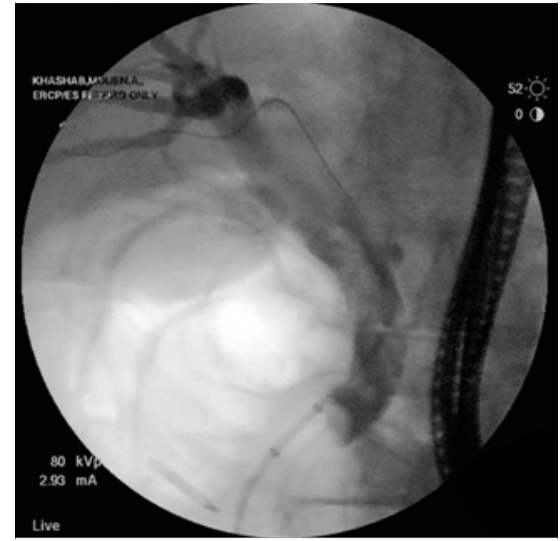

- Fig. 5 Fluoroscopic view: multiple sweeps were performed using an extraction balloon, and many small stones were removed.

Hopkins Medical Institutions, Baltimore,

Maryland, United States

\section{Corresponding author}

\section{Mouen A. Khashab, MD}

Johns Hopkins Hospital, 1800 Orleans Street, Sheikh Zayed Tower, Baltimore, MD 21287, United States

mkhasha1@jhmi.edu

\section{Bibliography}

DOI https://doi.org/10.1055/s-0043-105571

Endoscopy 2017; 49: 611-612

(c) Georg Thieme Verlag KG

Stuttgart $\cdot$ New York

ISSN 0013-726X

\section{ENDOSCOPY E-VIDEOS}

https://eref.thieme.de/e-videos

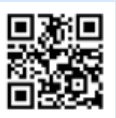

Endoscopy E-Videos is an openaccess online section, reporting on interesting cases and new

techniques in gastroenterological endoscopy. All papers include a high quality video and all contributions are freely accessible online.

This section has its own submission website at

https://mc.manuscriptcentral.com/e-videos 